\title{
Treatments to Promote Neural Repair after Stroke
}

\author{
Steven C. Cramer
}

Departments of Neurology, Anatomy \& Neurobiology and Physical Medicine \& Rehabilitation, University of California, Irvine, CA, USA

\begin{abstract}
Stroke remains a major cause of human disability worldwide. In parallel with advances in acute stroke interventions, new therapies are under development that target restorative processes. Such therapies have a treatment time window measured in days, weeks, or longer and so have the advantage that they may be accessible by a majority of patients. Several categories of restorative therapy have been studied and are reviewed herein, including drugs, growth factors, monoclonal antibodies, activity-related therapies including telerehabilitation, and a host of devices such as those related to brain stimulation or robotics. Many patients with stroke do not receive acute stroke therapies or receive them and do not derive benefit, often surviving for years thereafter. Therapies based on neural repair hold the promise of providing additional treatment options to a majority of patients with stroke.
\end{abstract}

\author{
Correspondence: Steven C. Cramer \\ Departments of Neurology, Anatomy \& \\ Neurobiology and Physical Medicine \& \\ Rehabilitation, UC Irvine Medical \\ Center, University of California, \\ 200 S. Manchester Ave, Suite 206, \\ Orange, CA 92868, USA \\ Tel:+1-714-456-6876 \\ Fax: +1-714-456-8805 \\ E-mail: scramer@uci.edu
}

Received: November 26, 2017

Revised: January 16, 2018

Accepted: January 18, 2018

Keywords Stroke; Neuronal plasticity; Stroke rehabilitation; Recovery of function; Telerehabilitation

\section{Introduction}

Neural repair can be defined as restoring the structure or function of the central nervous system (CNS) after injury such as stroke. Numerous categories of repair-based therapies are under study. Therapies based on repair are distinct from those based on prevention and from those that aim to reduce acute injury such as reperfusion or neuroprotection.

Repair-based therapies typically have a treatment time window measured in days-weeks or longer and so have the potential to be accessed by a large fraction of patients with stroke, including those with hemorrhagic stroke. This is a potential advantage for reducing the high burden of disability after stroke. In middleand high-income countries around the world, stroke is the leading neurological cause of lost disability-adjusted life years. ${ }^{1}$ Each year, 795,000 people in the United States experience a symptomatic stroke. An estimated 6,600,000 Americans adults have had a symptomatic stroke, with a prevalence that increases with age, and 13,000,000 people in the United States have had a si- lent stroke ${ }^{2}$ that while clinically inapparent at onset might nonetheless impact long-term function. The mean survival after stroke is 6 to 7 years, with approximately $85 \%$ of patients living past the first year of stroke. ${ }^{3}$ Thus, the majority of patients with stroke survive the acute episode and live with enduring disability for years to come.

Current acute stroke interventions reduce disability in only a limited fraction of patients. The only drug approved to treat acute stroke in the United States remains tissue plasminogen activator (tPA), ${ }^{4,5}$ which many patients do not receive ${ }^{6,7}$ largely due to its narrow treatment time window. A recent estimate is that approximately $5 \%$ of patients with stroke in the United States receive tPA acutely post-stroke. Importantly, half or more of those receiving intravenous tPA acutely post-stroke have significant long-term disability. ${ }^{4,5}$ An even small fraction of patients with acute stroke receive acute endovascular reperfusion therapies $^{8}$ although recent positive trials in this field are stimulating research into increasing the rate with which these interventions are given. Repair-based therapies complement acute therapies 
not only in terms of different biological targets but also in terms of treatment time window, measured in days to weeks or longer, and so have the potential to help a large proportion of patients affected by stroke.

\section{Spontaneous repair after stroke}

Neural repair after stroke arises spontaneously after stroke and continues for many weeks, possibly for years for some behaviors particularly language and cognition. Understanding spontaneous repair provides insights useful for treatment-related repair, a point that is underscored by the fact that treatments promoting repair are often provided in the context of spontaneous repair.

Stroke triggers several molecular cascades that produce injury, inflammation, or spontaneous repair. ${ }^{9}$ Animal studies have provided insights into stroke-induced recovery mechanisms. These are summarized here, but detailed reviews can be found elsewhere. ${ }^{10-17}$ An experimental stroke alters expression of numerous genes, ${ }^{13}$ leading to increases in levels of key growth factors, ${ }^{18,19}$ growth of synapses and dendrites, ${ }_{1}^{20,21}$ axonal remodeling and angiogenesis, ${ }^{22-25}$ and enhanced brain excitability mediated by alterations in glutamate and gamma-aminobutyric acid (GABA) receptor subtypes. ${ }^{26-29}$ These events are often concentrated in perilesional tissue but are not confined there; indeed, spontaneous growth-related changes following a unilateral infact arise broadly, within the contralesional hemispheres, ${ }^{20,30,31}$ in ipsilesional areas connected to the lesioned area ${ }_{1}{ }^{32}$ and even downstream in the spinal cord. ${ }^{33}$

Brain responses to a new unilateral stroke can be organized into three broad temporal epochs (Figure 1). The first epoch occurs during the initial hours after stroke onset and represents an opportunity to salvage threatened tissue, e.g., via reperfusion or neuroprotection. The second epoch commences days to weeks following stroke and corresponds to the peak weeks of spontaneous neural repair. Mechanisms of spontaneous recovery are most robust during this time. ${ }^{34}$ There are numerous specific time windows within this epoch which vary according to the gene or molecule of interest and which correspond to specific treatment time windows for treatment-induced neural repair after stroke. ${ }^{13,35}$ The third epoch represents a chronic phase whereby the brain is relatively stable with regards to endogenous repairrelated events, but modifications in brain structure and function are still possible with specific interventions. These three epochs delineate distinct biological states and have clinical implications with regards to delivery of restorative therapies.

Studies of spontaneous neural repair after stroke in human subjects generally rely on non-invasive methods, in comparison with the direct tissue-based measures employed in preclinical
Acute injury

- This phase is measured in hours and varies according to features of injury.

- The key therapeutic strategy here is to reduce the extent of injury.

- Main treatment approaches examined to date include

$\rightarrow$ reperfusion

neuroprotection

\section{Recovery stage}

- This phase of spectacular growth begins shortly after acute injury has stimulated restorative processes, evolves over several weeks, and varies in relation to factors such gene expression, molecular milieu, environment, and experience.

- This key therapeutic strategy here is to enhance the processes underlying spontaneous recovery. Other targets may be related to modifying inflammation, lifting diaschisis, or reducing late neuronal death. Acute injury is fixed and so its reduction is not a strategy during this stage.

- Main treatment approaches examined to date include

growth factors

- monoclonal antibodies

$\checkmark$ drugs

- cell-based therapies

activity-based therapies

brain stimulation

\section{Chronic state}

- This phase begins once spontaneous behavioral recovery has reached a plateau and the recovery stage critical period has ended. This phase typically occurs by three months post-strokes for the motor system, sometimes later in cognitive and language domains, and continues for the lifetime of the stroke survivor.

- This key therapeutic strategy here consists of interventions to induce a state of enhanced plasticity, given that the biological state of spontaneous recovery has receded.

- Main treatment approaches examined to date include

$\rightarrow$ drugs

$\checkmark$ cell-based therapies

activity-based therapies

brain stimulation

Figure 1. The brain progresses through three epochs after stroke. Each has a distinct biology defined by multiple processes ongoing in parallel. For each epoch, the general time scale, key therapeutic strategies, and main treatment approaches studied in preclinical and human studies are summarized.

investigations. The most commonly used methods include structural and functional magnetic resonance imaging, positron emission tomography, single photon emission computed tomography, electroencephalography, magnetoencephalography, transcranial magnetic stimulation (TMS), and near infrared spectroscopy; these provide a systems-level perspective on neural repair. ${ }^{34}$ These studies show anatomical changes such as thickened or thinned cortex in brain regions remote from stroke injury. ${ }^{36-39}$ Other studies have focused on functional changes, reporting 
modulation in local and distant cortical and subcortical activity, changes in interactions between hemispheres, shifts in cortical representational maps, and alterations in brain connectivity. ${ }^{34,40-42}$ These modulations in brain structure and function after stroke are of greatest benefit to patients with more severe injury ${ }^{43-48}$ and at times can be detrimental when present in patients with milder injury. The exact contribution that such findings make to behavioral recovery can be difficult to estimate across the human stroke population, where there are numerous sources of heterogeneity such as pre-stroke behavioral status, site and size of stroke-related brain injury, and choice of therapies following stroke. In general, return of functional anatomy towards normal patterns is associated with better behaioral outcomes. ${ }^{49}$

\section{Therapies to promote neural repair after stroke}

Numerous categories of post-stroke restorative therapy are under study, ${ }_{1}^{15,50-52}$ many in human trials. Most focus on a single agent or intervention, and with further understanding of monotherapies, combination therapies are likely to receive increased attention. As above, some restorative therapies are introduced within days of stroke onset and so interact with spontaneous neural repair mechanisms, and others are initiated months to years after stroke onset.

\section{Growth factors}

Growth factors have high potential as an approach to neural repair because they are important during normal CNS development and because they play a key role in spontaneous neural repair through mechanisms that include angiogenesis, cell proliferation and differentiation, migration, survival and apoptosis, synaptic plasticity, and immunomodulation. ${ }^{53,54}$ In some cases, a rich clinical experience exists for growth factors outside of stroke indications, such as for patients with renal failure or infertility. The utility of growth factors to promote stroke recovery has been studied in preclinical stroke studies. In many cases, preclinical studies suggest that administration of exogenous growth factors 24 hours or more following stroke onset provides a significant long-term benefit on behavioral outcomes. Examples of growth factors studied in the preclinical setting include brain-derived neurotrophic factor (BDNF) ${ }_{1}^{55}$ epidermal growth factor plus erythropoietin, ${ }^{56}$ and human chorionic gonadotropin (hCG) plus erythropoietin. ${ }^{57}$

Data in humans are more sparse regarding growth factor therapy after stroke as an approach to neural repair. Most trials to date have examined hematopoetic growth factors, which have a long record of safety in human applications. Granulocyte- colony stimulating factor (G-CSF) is one such growth factor that was evaluated in the AX200 for Ischemic Stroke (AXIS) study, ${ }^{58}$ which found that G-CSF given within 12 hours of stroke was safe and well-tolerated in 44 patients. A separate study of 60 patients also found G-CSF to be safe after stroke. ${ }^{59}$ However, a follow-up study, the AXIS-2 study, ${ }_{1}^{60}$ compared the middle G-CSF dose from the AXIS study $(135 \mu \mathrm{g} / \mathrm{kg})$ with placebo in $328 \mathrm{pa}-$ tients within 9 hours of stroke onset, using a multi-center, randomized, placebo-controlled study design. These authors found that G-CSF was not different from placebo on the primary endpoint, modified Rankin scale score at day 90 . A meta-analysis of studies introducing G-CSF days to years post-stroke did not find favorable effects. ${ }^{61}$

Erythropoietin has also been studied to promote neural repair. Preclinical studies suggest that systemically administered erythropoietin enters the brain and improves when delivered as a sole agent after acute injury is fixed, e.g., 24 after stroke onset. ${ }^{62}$ Erythropoietin was also found to be safe in a randomized, placebo-controlled study of 167 patients who received two doses of erythropoietin versus placebo beginning 48 hours after stroke. ${ }^{63}$ Other studies found favorable effects of sequential growth factor administration, giving a separate growth factor (epidermal growth factor ${ }^{56}$ or beta-hCG ${ }^{57}$ ) prior to erythropoietin, with the entire regimen initiated 1 to 7 days post-stroke, possibly by promoting neural stem cell proliferation.

The sequential growth factor approach was translated to humans in the Beta-hCG+Erythropoietin in Acute Stroke (BETAS) study, a single-dose, multisite, open-label, non-controlled safety trial that gave $3 \mathrm{hCG}$ doses beginning 1 to 2 days post-stroke followed by 3 erythropoietin doses beginning 7 to 8 days after stroke. This study identified no safety concerns, and eight of 12 patients had a day-90 Barthel index score $\geq 95 / 100 .{ }^{64}$ The BETAS study was followed by the REGENESIS study. ${ }^{65}$ This was intended to be a randomized, placebo-controlled, double-blind proof of concept study of sequential hCG (385 $\mu \mathrm{g}$ subcutaneous on day 1,3 , and 5 of study participation) and erythropoietin $(30,000 \mathrm{IU}$ intravenous on day 7,8 , and 9) using the BETAS study treatment schedule. This trial was put on hold by regulatory authorities due to concerns related to an acute stroke neuroprotective trial ${ }^{66}$ in which high dose erythropoietin $(40,000$ IU IV at $<6,24$, and 48 hours; cumulative dose 120,000 IU over $<48$ hours) was initiated within 6 hours of stroke onset, despite widely different time windows, and thus biological states in the CNS, as compared to REGENESIS: erythropoietin was initiated within 6 hours of stroke onset in the acute neuroprotective trial and 7 to 8 days after stroke onset in the REGENESIS trial. In that acute trial ${ }_{1}^{66}$ high dose erythropoietin was associated with significantly increased mortality relative to placebo, mainly intracerebral hemorrhage 
within the first week post-stroke, which was largely attributable to an interaction between erythropoietin and tPA co-administration-indeed $63 \%$ of enrollees in that study received thrombolytic therapy. Subsequently, the REGENESIS trial was modified to be a dose-ranging safety study and, due to financial constraints, largely moved to India. Enrollment was terminated by the sponsor early after 96 enrollees. In REGENESIS, sequential hCG+erythropoietin growth factor therapy was found to be safe; however, treatment groups did not differ in the primary endpoint, National Institutes of Health Stroke Scale (NIHSS) score change to day 90. However, it is uncertain whether study hypotheses were robustly tested in this trial, for example, 18\% of subjects dropped out, 31\% of enrollees had mulitiple assessors on the primary outcome measure over time despite pretrial training to use a single examiner, and only $23 \%$ of patients received even a single session of occupational therapy.

Growth factors are generally large proteins for which CNS ingress is limited. A number of strategies have been proposed to overcome this, such as helping growth factors to cross the blood-brain barrier via conjugation to a molecular Trojan horse. ${ }^{67}$ Another strategy has been to transfect an exogenous stem cell with a gene encoding for a growth factor, as has been studied for fibroblast growth factor- $2{ }_{1}^{68}$ glial cell line-derived neurotrophic factor ${ }^{69} \mathrm{BDNF}_{1}{ }^{70}$ vascular endothelial growth factor, ${ }^{71}$ placenta growth factor, ${ }_{1}^{72}$ or hepatocyte growth factor. ${ }^{73}$ Development of small ligands is another potential solution. ${ }^{74-76}$ Even if one assumes growth factor access to the CNS is limited after stroke, these molecules can nevertheless influence brain plasticity through extraneural targets, e.g., via the immune system.77,78

\section{Monoclonal antibodies}

The ability of other large biological molecules, such as monoclonal antibodies, to promote neural repair has also been evaluated. Monoclonal antibodies modulate activity within targeted signaling pathways by binding to specific targets such as receptors or cell surface markers. This approach has revolutionized patient care in numerous conditions, including neoplastic, immunological, and others. In the context of neural repair after stroke, monoclonocal antibodies have been used to neutralize molecules that inhibit growth in the CNS, with the overall appraoch being to produce a more permissive growth environment. Axonal growth has long been known to occur in the peripheral nervous system; ${ }^{79}$ however, in the CNS three major inhibitors (myelin-associated glycoprotein [MAG], oligo-myelin glycoprotein, and Nogo-A) reduce the extent to which the growth environment is permissive, a situation that is exacerbated by the increase of these molecules following stroke onset. ${ }^{13,80}$ Use of a monoclonal antibody to block these inhibitory molecules promotes axonal growth. ${ }^{81,82}$ One recent study randomized 42 patients with stroke to placebo versus one of three doses of intravenous GSK249320, a humanized IgG1 monoclonal antibody to MAG that has a disabled Fc region. Each patient received two infusions: the first administered 24 to 72 hours after stroke onset, and the second, 9 days later. No safety concerns were identified, ${ }_{1}^{83}$ and one of the secondary endpoints, gait velocity, showed a trend toward improvement with GSK249320 compared with placebo. However, a subsequent phase Illb double-blind, randomized, placebo-controlled study that enrolled 134 patients with ischemic stroke 24 to 72 hours prior found that two doses of the antibody was not superior to placebo for improving gait velocity. ${ }^{84}$ The antibody was well tolerated and showed low immunogenicity, findings that are potentially useful to future studies aiming to use a monoclonal antibody to modify activity in specific biological pathways to improve recovery from stroke.

\section{Drugs}

Numerous small molecules have also been examined to improve outcome after stroke. Small molecules may have advantages in terms of transport through the blood-brain barrier, with many being nonpolar and small in size, ${ }^{85}$ and thus often have high access to the brain. In many cases, candidate small molecules represent repurposed drugs, i.e., those already approved for other indications. Many of the small molecules studied for neural repair target a specific brain neurotransmitter system.

Monoaminergic drugs have been studied most often. An early focus for the field was on amphetamine ${ }_{1}^{86}$ which acts on multiple monoaminergic targets. The initial human experience in small trials was favorable ${ }^{87,88}$ but the Subacute Therapy with Amphetamine and Rehabilitation for Stroke (STARS) study was not. This randomized, double-blind, placebo-controlled trial did not demonstrate a benefit. ${ }^{89}$ The authors examined 5 weeks of twice-weekly amphetamine coupled with physiotherapy versus placebo coupled with physiotherapy in 71 patients enrolled 5 to 10 days post-stroke. The drug was safe but did not improve the primary outcome, motor recovery over 3 months using the arm/ leg Fugl-Meyer motor score, as compared to placebo. ${ }^{89}$ Strengths of this study include the use of a single therapist to administer all physiotherapy, use of a single examiner to assess study outcomes, which reduces variance and increases study power, and coupling drug exposure with training. A weakness of the study is that the treatment protocol was not directly translated from preclinical findings, and so the optimal dose, timing, and frequency of amphetamine to promote stroke recovery remains uncertain. It is difficult to determine whether STARS showed that amphetamine is not useful overall, or simply that the one protocol examined (twice weekly amphetamine beginning 5 to 10 
days post-stroke) is not useful.

The neurotransmitter dopamine regulates many aspects of neural functioning including excitability, synaptic transmission, plasticity, protein trafficking, and gene transcription. ${ }^{90}$ Not surprisingly, therefore, dopamine has a major role in numerous diverse brain processes such as movement, reward, learning, and plasticity. ${ }^{91}$ Furthermore, the role of dopamine in motor control is well established, with dopaminergic terminals in motor cortex contributing to cortical plasticity and playing a critical role in motor skill learning. ${ }^{92,93}$

Drugs that boost dopaminergic neurotransmission can improve learning and plasticity in healthy subjects. ${ }^{94}$ Similar results have been reported after stroke. A randomized, double-blind, placebocontrolled study in 53 patients within 6 months of stroke onset found that 3 weeks of $100 \mathrm{mg}$ of levodopa (in combination with a decarboxylase inhibitor, carbidopa, given once/day and combined with physical therapy) was significantly better than placebo combined with physical therapy on the primary endpoint, motor status by the Rivermead Motor Assessment after 3 weeks. ${ }^{95}$ This study awaits replication. Dopaminergic drugs have the potential advantage that measures of genetic variability may help predict intersubject differences in treatment response. ${ }^{96,97}$ Smaller studies using other dopamine agonists have been largely negative, e.g., a placebo-controlled, double-blind study of 33 patients 1 to 12 months post-stroke did not find a difference between a 9-week course of ropinirole+physiotherapy compared to placebo+physiotherapy on gait velocity. ${ }^{98}$ Small studies hint at the potential for noradrenergic drugs. ${ }^{99-101}$ Larger, well designed, fully powered trials are needed in this promising area of research.

Serotonin, another monoaminergic neurotransmitter, may also be helpful for promoting neural repair and improving stroke recovery. Serotonin normally plays a role in modulating multiple brain functions, particularly cognitive functions such as response inhibition and memory consolidation, and this neurotransmitter also modulates the impact of punishment-related signals on learning and emotion. ${ }^{102-104}$ Earlier reports supported the potential utility of selective serotonin reuptake inhibitor (SSRI) drugs for improving motor outcomes after stroke. ${ }^{105-108}$ Recent reports remain supporting, suggesting that boosting serotonin neurotransmission improves stroke recovery. Robinson et al. ${ }^{109}$ performed a multisite, randomized controlled trial for prevention of depression among 176 non-depressed patients enrolled within 3 months of stroke onset. Patients randomized to the placebo arm were significantly $(P<0.001)$ more likely to reach the primary outcome, development of major or minor depression, as compared to patients in either of the two active comparator arms, which were (1) the SSRI escitalopram or (2) problem-solving therapy. One analysis of a subgroup of these patients found that cognitive outcomes at 12 months were significantly better among those randomized to escitalopram, independent of depression, while a separate subgroup analysis found a lower incidence of generalized anxiety disorder with escitalopram or with problem-solving therapy. ${ }^{10}$

The strongest evidence in support of an SSRI to improve outcomes after stroke comes from The Fluoxetine for Motor Recovery After Acute Ischemic Stroke (FLAME) study. ${ }^{11}$ This was a double-blind, placebo-controlled trial that enrolled non-depressed hemiplegic/hemiparetic patients 5 to 10 days after onset of ischemic stroke. Patients were randomized to 3 months of oral fluoxetine $(20 \mathrm{mg} /$ day) versus placebo. Those randomized to fluoxetine showed significantly greater gains on the primary endpoint, change in the arm/leg Fugl-Meyer motor score from baseline to day 90 ( $P=0.003)$, a remarkable 9.7 point difference between treatment arms on this 100 point scale, though this result must be interpreted in light of the fact that a small, nonsignificant difference in baseline scores favored the SSRI-treated group. Phase 3 trials are underway to further evaluate this finding. Measures of genetic variability may inform likelihood of response to a serotonergic drugs. ${ }^{112,113}$

Kim et al. ${ }^{114}$ randomized 478 patients in Korea with recent ( $<21$ days) ischemic or hemorrhagic stroke to oral escitalopram (10 mg/day) or placebo for 3 months. Patients with a history of severe depression were excluded. At baseline, enrollees overall had mild strokes (average baseline NIHSS score of 4.8) and mild depression (Montgomery-Åsberg Depression Rating Scale score 10.7), with approximately one-fourths showing moderate or severe depressive symptoms. While the drug was well tolerated, the frequency of the primary endpiont, moderate or severe depressive symptoms after 3 months defined as Montgomery-Asberg Depression Rating Scale $\geq 16$, was not different between the two treatment arms. A shift analysis did find a significant benefit of escitalopram, mainly due to a reduced number of patients with mild depressive symptoms at 3 months $(P=0.044)$, and the drug also significantly reduced anger symptoms. Post hoc analysis found that the number of patients with zero or minimal depressive symptoms at 3 months was significantly higher in the escitalopram group, suggesting directions for endpoint selection for future trials of SSRI after stroke. A measure of motor function at 3 months also did not differ between treatment groups, in response to which the authors speculate that SSRIs might improve motor dysfunction after acute stroke only in patients lacking early depression.

Norepinephrine transmission as a drug target has received limited study to date in the context of stroke recovery. Normally, noradrenergic neurotransmission broadly amplifies neuronal activity, increases the general level of excitability, and selectively 
amplifies activities evoked by unexpected inputs. ${ }^{115}$ This effect of norepinephrine on regulating overall arousal levels has a modulatory effect on executive function. ${ }^{103}$ To date there has been only a handful of studies of noradrenergic drugs to promote stroke recovery. These have been small in size but showed promising results. 100,116,117

Drugs that modulate neurotransmission in acetylcholinergic pathways have also received limited study in relation to neural repair. Acetylcholine inputs to neocortex are important to procedural memory and operant conditioning. ${ }^{118}$ Acetylcholine enables plasticity by selectively amplifying anticipated inputs and weakening non-anticipated inputs. ${ }^{115}$ Modulation of nicotinic cholinergic neurotransmission alters attention, while muscarinic cholinergic receptors play a greater role in cognitive flexibility. ${ }^{103} \mathrm{Lu}-$ ria ${ }^{119}$ long ago advocated for cholinergic therapies as a major pathway to enhancing recovery after brain damage. Studies in rodents ${ }^{120,121}$ and primates ${ }^{122}$ with experimental stroke support this view, but data from human subjects with stroke remain sparse, ${ }_{1}^{123}$ though preliminary studies have been favorable. ${ }^{124,125}$ Data with respect to non-motor aspects of stroke recovery are limited in quantity but potentially promising, ${ }^{123,124,126}$ and a recent study in 33 patients found that donepezil to be safe when initiated within 24 hours of stroke onset. ${ }^{124}$

Other small molecules have been studied. Evidence suggests potential utility of drugs that modulate $\mathrm{GABA}^{28}$ or glutamate ${ }^{27,127}$ receptors, and these effects may be particularly dependent on the time post-stroke when the agent is introduced. Sildenafil is a phosphodiesterase type 5 inhibitor that has shown promise as a restorative agent post-stroke ${ }^{128,129}$ and has been tested in human subjects recovering from stroke. ${ }^{130}$

\section{Cell-based therapies}

Cell-based therapies are receiving increased attention, with many types of cell-based therapy under study. ${ }^{131,132}$ Examples include transformed tumor cells, adult stem cells such as marrow stromal cells, umbilical cord cells, placental cells, embryonic stem cells, fetal stem cells, and induced pluripotent cells. Cells may be administered alone or with a bioscaffold, with genes modified, or after exposure to particular culture conditions such as low oxygen or neurotrophin exposure. Stem cells may be autologous, allogeneic, or xenografts.

Considerable attention has been drawn to mesenchymal stromal cells (MSCs), which are an adult non-hematopoietic pluripotent cell. Abundant preclinical evidence suggests that MSCs improve behavioral outcomes after experimental stroke via several different mechanisms in parallel, ${ }^{133}$ a potential advantage over pharmacological therapies that act via a single treatment mechanism, ${ }^{134-136}$ and with a time window that is measured in days or weeks post-stroke. A meta-analysis examined 46 preclinical studies in which MSC was given after cerebral ischemia. ${ }^{137}$ MSC improved outcomes in 44 of the 46 studies. The mean effect size for MSC administration was consistently very large, e.g., averaging 1.78 for the modified Neurological Severity Score across 28 studies; results were similar overall when analyses were restricted to studies that initiated MSC $\geq 24$ hours after stroke onset. Early phase clinical studies to date are promising. ${ }^{138-142}$

Cellular therapies can introduce challenges that are uncommon with other classes of restorative therapy. For example, such therapies are not a drug or a device but instead consist of living cells. As such, the biological potency and identity of the therapy can change over time, e.g., during storage or shipping. Some stem cells can persist for months or even years after administration and so require prolonged periods of assessment after implantation. Certain cells generate ethical concerns among some patients and scientists. ${ }^{143}$

\section{Activity-based therapies}

A number of intensive activity-based therapy regimens have been studied, targeting motor deficits, aphasia, and other forms of impairment after stroke. For example, constraint-induced movement therapy trains the affected limb while restraining the non-affected limb in order to overcome learned disuse of the affected limb. In the Extremity Constraint Induced Therapy Evaluation (EXCITE) trial, constraint-induced therapy was associated with significant gains in motor outcome in 222 patients enrolled 3 to 9 months after stroke onset, ${ }_{1}^{144}$ with these effects remaining significant for years. ${ }^{145}$ This approach has also been studied in patients with aphasia. ${ }^{146}$ The timing of intensive therapies is important. The Very Early Constraint-Induced Movement during Stroke Rehabilitation (VECTORS) trial examined constraint-induced movement therapy early after stroke. Among 52 patients enrolled within 1 month of stroke onset, higher intensity of therapy was associated with poorer behavioral outcome at day $90^{147}-$ a very high dose of activity too early after stroke might be net harmful. The Locomotor Experience Applied Post-Stroke (LEAPS) trial compared two therapies focused on gait in 408 patients within 2 months of stroke, and found that treadmill training with body-weight support did not differ from progressive exercise at home managed by a physical therapist in effects on walking ability 1 year after stroke. ${ }^{148}$ Importantly, the LEAPS trial found that a majority of patients with stroke can experience significant behavioral gains when therapy is initiated many weeks after stroke onset, with 52\% of treated patients showing improved gait velocity 1 year after stroke onset. Two recent trials compared different activity-related therapy in the subacute ${ }^{149}$ or chronic $^{150}$ phase after stroke and did not see a difference in 
treatment gains in relation to dose of therapy. One interpretation of these two findings is that the doses studied, $30^{149}$ or $32^{150}$ hours of activity-based intervention, were too low and that very high doses of activity-based therapy may be key to improving patient function, similar to the need for very high amounts of motor practice to show substantial improvement in motor skills among healthy persons.

\section{Robotic and telehealth devices}

The effect of therapy delivered by robotic devices has also been examined. Numerous robotic devices have been studied. ${ }^{151-155}$ These devices offer potential advantages, such as consistent and long-lasting output, programmability, utility for virtual reality applications, safety, high precision, the potential for an improved therapist:patient ratio, and great potential for telerehabilitation and therefore ability to reach underserved regions. ${ }^{156}$ However, concerns exist with some aspects of robot-based intervention, for example, the need to understand the mechanism of action, the response of the therapist community to a robotic device, the response of patients to reduced interaction with a human therapist, the effect of such devices on task ecology and object affordance, the limited repertoire that fixed devices have, and the nature of the measurements that a robot is programmed to report.

In one of the largest studies of robot therapy after stroke, Lo et al. ${ }^{157}$ enrolled 127 patients in the chronic phase of stroke and found that robot-assisted therapy did not significantly improve motor function after 12 weeks, as compared with usual care or intensive therapy; in secondary analyses, robot-assisted therapy improved outcomes over 36 weeks as compared with usual care but not with intensive therapy. This study may be complicated by the fact that enrollees had relatively severe motor deficits.

Robotic devices have great promise but further research is needed. One recent review noted that (1) effects on motor control are small and specific to the joints targeted by the robotic intervention; (2) limited data support generalization of robotderived gains to broader functions; and (3) little data exist among patients in the initial weeks following stroke onset. ${ }^{155}$ Factors that might represent avenues for improving the impact of robotic therapy include more fully defining the relationship between robotic therapy and traditional physiotherapy, and matching the right patients with the right robotic devices and protocols.

Telehealth approaches are receiving increased attention due to their ability to provide high doses of therapy in a simple, efficient, and accessible manner that can extend the resources clinicians can provide to stroke survivors. ${ }^{158}$ There are many different approaches under study, targeting various neurological deficits, using divergent methods to drive patient behavior, and in some cases combining rehabilitation and prevention strategies via the same system. ${ }^{159-163}$ We recently evaluated a home-based telerehabilitation system in patients with chronic hemiparetic stroke with onset 3 to 24 months prior and stable arm motor deficits. ${ }^{164}$ Enrollees received 28 days of telerehabilitation using a system delivered to their home, with each day consisting of one structured hour focused on individualized exercises and games, stroke education, plus an hour of free play. Compliance was excellent: participants engaged in therapy on 329 of 336 assigned days (97.9\%). Arm repetitions across the 28 days averaged 24,607 $\pm 9,934$ per participant. Arm motor status showed significant gains (change in the Fugl-Meyer score of $4.8 \pm 3.8$ points, $P=0.0015$ ), with half of the participants exceeding the minimal clinically important difference. Although scores on tests of computer literacy declined with age $(r=-0.92, P<0.0001)$, neither the motor gains nor the amount of system use varied with computer literacy. Daily stroke education via the telerehabilitation system was associated with a 39\% increase in stroke prevention knowledge $(P=0.0007)$. Depression scores obtained in person correlated with scores obtained via the telerehabilitation system 16 days later $(r=0.88, P=0.0001)$. In-person blood pressure values closely matched those obtained via this system ( $r=0.99, P<0.0001)$. Based on these findings a phase II trial is underway, the results of which are expected to be announced in 2018. ${ }^{165}$

\section{Brain stimulation}

The brain is an electrical organ and expends considerable energy maintaining a specific cellular resting potential. Not surprisingly, therefore, electrical and electromagnetic interventions have the potential to modify brain function and potentially promote neural repair to improve outcomes after stroke. Many forms of brain stimulation have been studied after stroke, including repetitive TMS, theta burst stimulation, epidural cortical stimulation, transcranial direct current stimulation, transcranial alternating current stimulation, and stimulation via a laser-based device. ${ }^{166} \mathrm{~A}$ related intervention, vagal nerve stimulation, has also been evaluated in early phase clinical trials. ${ }^{167}$ There is precedence for a focus on brain stimulation, as the gold standard therapy for major depression remains a form of brain stimulation-electroconvulsive therapy, ${ }^{168}$ and repetitive TMS has been approved by the U.S. Food and Drug Administration for the treatment of major depression. ${ }^{169}$ Some results with brain stimulation to promote improved outcomes after stroke, mainly targeting motor outcomes, have been favorable ${ }^{170,171}$ while others have not. ${ }^{172,173}$ Large, well designed trials are needed, and further study of nonmotor endpoints is also critical. A phase III trial aiming to improve arm motor outcomes in patients with chronic hemiparetic stroke examined neurosurgically implanted epidural cortical 
stimulation plus physical therapy but did not find this intervention to be significantly different from physical therapy alone ${ }_{i}^{174}$ post hoc analysis indicated response to brain stimulation was substantially greater among subjects with preservation of physiological integrity or with subtotal injury to key motor system anatomical structures, suggesting the ability to stratify patients to reduce trial variance and increase effect sizes. ${ }^{36}$

\section{Conclusions}

Preclinical studies have suggested a large number of therapies that may have to improve recovery from stroke. These are in various stages of translation, with most at an early point of clinical trials. Principles of promoting neuroplasticity in a clinical setting are emerging and have been reviewed elsewhere. ${ }^{175-177}$ Issues unique to stroke recovery and rehabilitation studies are increasingly being recognized ${ }^{178-180}$ and are important to effective clinical research in this area. Many patients do not reach the hospital in time to receive interventions that can reverse a stroke, and half of those who do receive such therapies still show significant long-term disability. Restorative therapies that aim to harness clinical neuroplasticity may be accessible by a large fraction of patients with stroke and so hold the promise to reduce deficits and improve function for a majority stroke survivors.

\section{Disclosure}

Steven C. Cramer has served as a consultant for Roche, Dart Neuroscience, and MicroTransponder.

\section{Acknowledgments}

Supported by a grant from the U.S. National Institutes of Health (K24 HD074722).

\section{References}

1. Johnston SC, Hauser SL. Neurological disease on the global agenda. Ann Neurol 2008;64:A11-A12.

2. Writing Group Members, Mozaffarian D, Benjamin E, Go AS, Arnett DK, Blaha MJ, et al. Heart disease and stroke statistics-2016 update: a report from the American Heart Association. Circulation 2016;133:e38-e360.

3. WRITING GROUP MEMBERS, Lloyd-Jones D, Adams RJ, Brown TM, Carnethon M, Dai S, et al. Heart disease and stroke statistics: 2010 update: a report from the American Heart Association. Circulation 2010;121:e46-e215.

4. Hacke W, Kaste M, Bluhmki E, Brozman M, Dávalos A, Guidetti
D, et al. Thrombolysis with alteplase 3 to 4.5 hours after acute ischemic stroke. N Eng/ J Med 2008;359:1317-1329.

5. National Institute of Neurological Disorders and Stroke rt-PA Stroke Study Group. Tissue plasminogen activator for acute ischemic stroke. N Engl J Med 1995;333:1581-1587.

6. Reed SD, Cramer SC, Blough DK, Meyer K, Jarvik JG. Treatment with tissue plasminogen activator and inpatient mortality rates for patients with ischemic stroke treated in community hospitals. Stroke 2001;32:1832-1840.

7. Adeoye 0 , Hornung $R$, Khatri $P$, Kleindorfer D. Recombinant tissue-type plasminogen activator use for ischemic stroke in the United States: a doubling of treatment rates over the course of 5 years. Stroke 2011;42:1952-1955.

8. Goyal M, Menon BK, van Zwam WH, Dippel DW, Mitchell PJ, Demchuk AM, et al. Endovascular thrombectomy after largevessel ischaemic stroke: a meta-analysis of individual patient data from five randomised trials. Lancet 2016;387:1723-1731.

9. Overman JJ, Carmichael ST. Plasticity in the injured brain: more than molecules matter. Neuroscientist 2014;20:15-28.

10. Cramer SC, Chopp M. Recovery recapitulates ontogeny. Trends Neurosci 2000;23:265-271.

11. Wieloch T, Nikolich K. Mechanisms of neural plasticity following brain injury. Curr Opin Neurobiol 2006;16:258-264.

12. Nudo RJ. Neural bases of recovery after brain injury. $J$ Commun Disord 2011:44:515-520.

13. Li S, Carmichael ST. Growth-associated gene and protein expression in the region of axonal sprouting in the aged brain after stroke. Neurobiol Dis 2006;23:362-373.

14. Arai $\mathrm{K}, \mathrm{Lo}$ EH. Experimental models for analysis of oligodendrocyte pathophysiology in stroke. Exp Trans/ Stroke Med 2009;1:6.

15. Zhang ZG, Chopp M. Neurorestorative therapies for stroke: underlying mechanisms and translation to the clinic. Lancet Neurol 2009;8:491-500.

16. Carmichael ST. Cellular and molecular mechanisms of neural repair after stroke: making waves. Ann Neurol 2006;59:735742.

17. Murphy $T H$, Corbett D. Plasticity during stroke recovery: from synapse to behaviour. Nat Rev Neurosci 2009;10:861-872.

18. Finklestein SP, Caday CG, Kano M, Berlove DJ, Hsu CY, Moskowitz $\mathrm{M}$, et al. Growth factor expression after stroke. Stroke 1990;21(11 Suppl):III122-IIII24.

19. Kawamata T, Speliotes EK, Finklestein SP. The role of polypeptide growth factors in recovery from stroke. In: Freund HJ, Sabel BA, Witte OW. Brain Plasticity Advances in Neurology. Vol. 73. Philadelphia, PA: Lippincott-Raven, 1997:377-382.

20. Jones TA, Kleim JA, Greenough WT. Synaptogenesis and dendritic growth in the cortex opposite unilateral sensorimotor cortex damage in adult rats: a quantitative electron micro- 
scopic examination. Brain Res 1996;733:142-148.

21. Jones TA, Schallert T. Overgrowth and pruning of dendrites in adult rats recovering from neocortical damage. Brain Res 1992;581:156-160.

22. Ding G, Jiang $Q$, Li L, Zhang L, Zhang ZG, Ledbetter KA, et al. Magnetic resonance imaging investigation of axonal remodeling and angiogenesis after embolic stroke in sildenafiltreated rats. J Cereb Blood Flow Metab 2008;28:1440-1448.

23. Seevinck PR, Deddens LH, Dijkhuizen RM. Magnetic resonance imaging of brain angiogenesis after stroke. Angiogenesis 2010;13:101-111.

24. Teng H, Zhang ZG, Wang L, Zhang RL, Zhang L, Morris D, et al. Coupling of angiogenesis and neurogenesis in cultured endothelial cells and neural progenitor cells after stroke. J Cereb Blood Flow Metab 2008;28:764-771.

25. Hermann DM, Chopp M. Promoting brain remodelling and plasticity for stroke recovery: therapeutic promise and potential pitfalls of clinical translation. Lancet Neurol 2012;11:369380.

26. Redecker $\mathrm{C}$, Wang W, Fritschy JM, Witte OW. Widespread and long-lasting alterations in GABA(A)-receptor subtypes after focal cortical infarcts in rats: mediation by NMDA-dependent processes. J Cereb Blood Flow Metab 2002;22:1463-1475.

27. Clarkson AN, Overman JJ, Zhong S, Mueller R, Lynch G, Carmichael ST. AMPA receptor-induced local brain-derived neurotrophic factor signaling mediates motor recovery after stroke. J Neurosci 2011;31:3766-3775.

28. Clarkson AN, Huang BS, Macisaac SE, Mody I, Carmichael ST. Reducing excessive GABA-mediated tonic inhibition promotes functional recovery after stroke. Nature 2010;468:305-309.

29. Que $M$, Schiene $K$, Witte OW, Zilles K. Widespread up-regulation of $\mathrm{N}$-methyl-D-aspartate receptors after focal photothrombotic lesion in rat brain. Neurosci Lett 1999;273:77-80.

30. Kawamata T, Dietrich WD, Schallert T, Gotts JE, Cocke RR, Benowitz LI, et al. Intracisternal basic fibroblast growth factor enhances functional recovery and up-regulates the expression of a molecular marker of neuronal sprouting following focal cerebral infarction. Proc Natl Acad Sci U S A 1997;94:81798184.

31. Dijkhuizen RM, van der Marel K, Otte WM, Hoff El, van der Zijden JP, van der Toorn A, et al. Functional MRI and diffusion tensor imaging of brain reorganization after experimental stroke. Trans/ Stroke Res 2012;3:36-43.

32. Dancause N, Barbay S, Frost SB, Plautz EJ, Chen D, Zoubina $\mathrm{EV}$, et al. Extensive cortical rewiring after brain injury. J Neurosci 2005;25:10167-10179.

33. Sist B, Fouad K, Winship IR. Plasticity beyond peri-infarct cortex: spinal up regulation of structural plasticity, neuro- trophins, and inflammatory cytokines during recovery from cortical stroke. Exp Neurol 2014;252:47-56.

34. Cramer SC. Repairing the human brain after stroke: I. mechanisms of spontaneous recovery. Ann Neurol 2008;63:272-287.

35. Ren J, Kaplan PL, Charette MF, Speller H, Finklestein SP. Time window of intracisternal osteogenic protein-1 in enhancing functional recovery after stroke. Neuropharmacology 2000;39: 860-865.

36. Nouri S, Cramer SC. Anatomy and physiology predict response to motor cortex stimulation after stroke. Neurology 2011;77:1076-1083.

37. Duering $M$, Righart $R$, Csanadi $E_{1}$ Jouvent $E_{1}$ Herve $D$, Chabriat $\mathrm{H}_{\text {, et }}$ al. Incident subcortical infarcts induce focal thinning in connected cortical regions. Neurology 2012;79:2025-2028.

38. Duering $M$, Righart $R$, Wollenweber FA, Zietemann V, Gesierich $B$, Dichgans $M$. Acute infarcts cause focal thinning in remote cortex via degeneration of connecting fiber tracts. Neurology 2015;84:1685-1692.

39. Gauthier LV, Taub E, Mark WW, Barghi A, Uswatte G. Atrophy of spared gray matter tissue predicts poorer motor recovery and rehabilitation response in chronic stroke. Stroke 2012;43:453457.

40. Grefkes C, Ward NS. Cortical reorganization after stroke: how much and how functional? Neuroscientist 2014;20:5670.

41. Stinear CM, Byblow WD, Ward SH. An update on predicting motor recovery after stroke. Ann Phys Rehabil Med 2014;57:489498.

42. Cassidy JM, Cramer SC. Spontaneous and therapeutic-induced mechanisms of functional recovery after stroke. Transl Stroke Res 2017;8:33-46.

43. Lotze M, Markert J, Sauseng P, Hoppe J, Plewnia C, Gerloff C. The role of multiple contralesional motor areas for complex hand movements after internal capsular lesion. J Neurosci 2006;26:6096-6102.

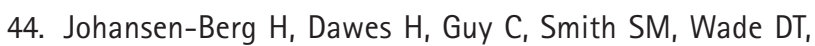
Matthews PM. Correlation between motor improvements and altered fMRI activity after rehabilitative therapy. Brain 2002;125(Pt 12):2731-2742.

45. Bradnam LV, Stinear CM, Barber PA, Byblow WD. Contralesional hemisphere control of the proximal paretic upper limb following stroke. Cereb Cortex 2012;22:2662-2671.

46. Netz J, Lammers T, Hömberg V. Reorganization of motor output in the non-affected hemisphere after stroke. Brain 1997;120(Pt 9):1579-1586.

47. Turton A, Wroe S, Trepte N, Fraser C, Lemon RN. Contralateral and ipsilateral EMG responses to transcranial magnetic stimulation during recovery of arm and hand function after 
stroke. Electroencephalogr Clin Neurophysiol 1996;101:316328.

48. Heiss WD, Thiel A. A proposed regional hierarchy in recovery of post-stroke aphasia. Brain Lang 2006;98:118-123.

49. Ward NS, Brown MM, Thompson AJ, Frackowiak RS. Neural correlates of motor recovery after stroke: a longitudinal fMRI study. Brain 2003;126(Pt 11):2476-2496.

50. Cramer SC. Repairing the human brain after stroke. II. Restorative therapies. Ann Neurol 2008;63:549-560.

51. Cumberland Consensus Working Group, Cheeran B, Cohen $L$, Dobkin B, Ford G, Greenwood R, et al. The future of restorative neurosciences in stroke: driving the translational research pipeline from basic science to rehabilitation of people after stroke. Neurorehabil Neural Repair 2009;23:97-107.

52. Knecht S, Hesse S, Oster P. Rehabilitation after stroke. Dtsch Arztebl Int 2011;108:600-606.

53. Lanfranconi S, Locatelli F, Corti S, Candelise L, Comi GP, Bar-

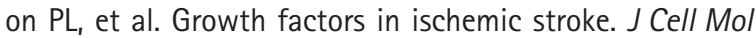
Med 2011;15:1645-1687.

54. Oliveira SL, Pillat MM, Cheffer A, Lameu C, Schwindt T, UIrich $H$. Functions of neurotrophins and growth factors in neurogenesis and brain repair. Cytometry A 2013;83:76-89.

55. Ren JM, Finklestein SP. Growth factor treatment of stroke. Curr Drug Targets CNS Neurol Disord 2005;4:121-125.

56. Kolb B, Morshead C, Gonzalez C, Kim M, Gregg C, Shingo T, et al. Growth factor-stimulated generation of new cortical tissue and functional recovery after stroke damage to the motor cortex of rats. J Cereb Blood Flow Metab 2007;27:983-997.

57. Belayev L, Khoutorova L, Zhao KL, Davidoff AW, Moore AF, Cramer SC. A novel neurotrophic therapeutic strategy for experimental stroke. Brain Res 2009;1280:117-123.

58. Schäbitz WR, Laage R, Vogt G, Koch W, Kollmar R, Schwab S, et al. AXIS: a trial of intravenous granulocyte colony-stimulating factor in acute ischemic stroke. Stroke 2010;41:25452551.

59. England TJ, Abaei M, Auer DP, Lowe J, Jones DR, Sare G, et al. Granulocyte-colony stimulating factor for mobilizing bone marrow stem cells in subacute stroke: the stem cell trial of recovery enhancement after stroke 2 randomized controlled trial. Stroke 2012;43:405-411.

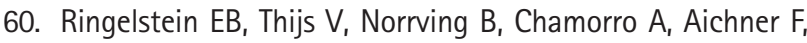
Grond $\mathrm{M}$, et al. Granulocyte colony-stimulating factor in patients with acute ischemic stroke: results of the AX200 for Ischemic Stroke trial. Stroke 2013;44:2681-2687.

61. England TJ, Sprigg N, Alasheev AM, Belkin AA, Kumar A, Prasad $\mathrm{K}$, et al. Granulocyte-colony stimulating factor (G-CSF) for stroke: an individual patient data meta-analysis. Sci Rep 2016;6:36567.
62. Jerndal M, Forsberg K, Sena ES, Macleod MR, O'Collins VE, Linden $T$, et al. A systematic review and meta-analysis of erythropoietin in experimental stroke. J Cereb Blood Flow Metab 2010;30:961-968.

63. Yip HK, Tsai TH, Lin HS, Chen SF, Sun CK, Leu S, et al. Effect of erythropoietin on level of circulating endothelial progenitor cells and outcome in patients after acute ischemic stroke. Crit Care 2011;15:R40.

64. Cramer SC, Fitzpatrick C, Warren M, Hill MD, Brown D, Whitaker $\mathrm{L}$, et al. The beta-hCG+erythropoietin in acute stroke (BETAS) study: a 3-center, single-dose, open-label, noncontrolled, phase lla safety trial. Stroke 2010;41:927-931.

65. Cramer SC, Hill MD, REGENESIS-LED Investigators. Human choriogonadotropin and epoetin alfa in acute ischemic stroke patients (REGENESIS-LED trial). Int J Stroke 2014;9:321-327.

66. Ehrenreich $H$, Weissenborn $K$, Prange $H$, Schneider D, Weimar

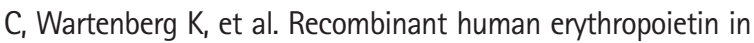
the treatment of acute ischemic stroke. Stroke 2009;40:e647e656.

67. Zhang Y, Pardridge WM. Blood-brain barrier targeting of BDNF improves motor function in rats with middle cerebral artery occlusion. Brain Res 2006;1111:227-229.

68. Kim BO, Tian H, Prasongsukarn K, Wu J, Angoulvant D, Wnendt $S$, et al. Cell transplantation improves ventricular function after a myocardial infarction: a preclinical study of human unrestricted somatic stem cells in a porcine model. Circulation 2005;112(9 Suppl):I96-I104.

69. Horita Y, Honmou O, Harada K, Houkin K, Hamada H, Kocsis JD. Intravenous administration of glial cell line-derived neurotrophic factor gene-modified human mesenchymal stem cells protects against injury in a cerebral ischemia model in the adult rat. J Neurosci Res 2006;84:1495-1504.

70. Zhao LX, Zhang J, Cao F, Meng L, Wang DM, Li YH, et al. Modification of the brain-derived neurotrophic factor gene: a portal to transform mesenchymal stem cells into advantageous engineering cells for neuroregeneration and neuroprotection. Exp Neurol 2004;190:396-406.

71. Iwase T, Nagaya N, Fujii T, Itoh T, Murakami S, Matsumoto T, et al. Comparison of angiogenic potency between mesenchymal stem cells and mononuclear cells in a rat model of hindlimb ischemia. Cardiovasc Res 2005;66:543-551.

72. Liu H, Honmou O, Harada K, Nakamura K, Houkin K, Hamada H, et al. Neuroprotection by PIGF gene-modified human mesenchymal stem cells after cerebral ischaemia. Brain 2006;129(Pt 10):2734-2745.

73. Zhao MZ, Nonoguchi N, Ikeda N, Watanabe T, Furutama D, Miyazawa $D$, et al. Novel therapeutic strategy for stroke in rats by bone marrow stromal cells and ex vivo HGF gene transfer with 
HSV-1 vector. J Cereb Blood Flow Metab 2006;26:1176-1188.

74. Hermann DM. Enhancing the delivery of erythropoietin and its variants into the ischemic brain. ScientificWorldJournal 2009;9:967-969.

75. Zhang Y, Pardridge WM. Conjugation of brain-derived neurotrophic factor to a blood-brain barrier drug targeting system enables neuroprotection in regional brain ischemia following intravenous injection of the neurotrophin. Brain Res 2001;889:4956.

76. Yasuhara T, Borlongan CV, Date I. Ex vivo gene therapy: transplantation of neurotrophic factor-secreting cells for cerebral ischemia. Front Biosci 2006;11:760-775.

77. Wattananit S, Tornero D, Graubardt N, Memanishvili T, Monni E, Tatarishvili J, et al. Monocyte-derived macrophages contribute to spontaneous long-term functional recovery after stroke in mice. J Neurosci 2016;36:4182-4195.

78. Ziv Y, Ron N, Butovsky O, Landa G, Sudai E, Greenberg N, et al. Immune cells contribute to the maintenance of neurogenesis and spatial learning abilities in adulthood. Nat Neurosci 2006;9:268-275.

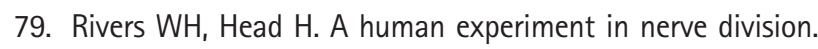
Brain 1908;31:323-450.

80. Cheatwood JL, Emerick AJ, Schwab ME, Kartje GL. Nogo-A expression after focal ischemic stroke in the adult rat. Stroke 2008;39:2091-2098.

81. Domeniconi M, Filbin MT. Overcoming inhibitors in myelin to promote axonal regeneration. J Neurol Sci 2005;233:43-47.

82. Buchli $A D$, Schwab ME. Inhibition of Nogo: a key strategy to increase regeneration, plasticity and functional recovery of the lesioned central nervous system. Ann Med 2005;37:556-567.

83. Cramer SC, Abila B, Scott NE, Simeoni M, Enney LA; MAG111539 Study Investigators. Safety, pharmacokinetics, and pharmacodynamics of escalating repeat doses of GSK249320 in patients with stroke. Stroke 2013;44:1337-1342.

84. Cramer SC, Enney LA, Russell CK, Simeoni M, Thompson TR. Proof-of-concept randomized trial of the monoclonal antibody GSK249320 versus placebo in stroke patients. Stroke 2017;48:692-698.

85. Pardridge WM. Drug transport across the blood-brain barrier. J Cereb Blood Flow Metab 2012;32:1959-1972.

86. Feeney DM, Gonzalez A, Law WA. Amphetamine, haloperidol, and experience interact to affect rate of recovery after motor cortex injury. Science 1982;217:855-857.

87. Crisostomo EA, Duncan PW, Propst M, Dawson DV, Davis JN. Evidence that amphetamine with physical therapy promotes recovery of motor function in stroke patients. Ann Neurol 1988; 23:94-97.

88. Walker-Batson D, Smith $P$, Curtis $S$, Unwin H, Greenlee R. Am- phetamine paired with physical therapy accelerates motor recovery after stroke. Further evidence. Stroke 1995;26:22542259.

89. Gladstone DJ, Danells CJ, Armesto A, Mcllroy WE, Staines WR, Graham SJ, et al. Physiotherapy coupled with dextroamphetamine for rehabilitation after hemiparetic stroke: a randomized, double-blind, placebo-controlled trial. Stroke 2006;37:179-185.

90. Tritsch NX, Sabatini BL. Dopaminergic modulation of synaptic transmission in cortex and striatum. Neuron 2012;76:33-50.

91. McAllister TW. Polymorphisms in genes modulating the dopamine system: do they inf luence outcome and response to medication after traumatic brain injury? J Head Trauma Rehabil 2009;24:65-68.

92. Molina-Luna K, Pekanovic A, Röhrich S, Hertler B, SchubringGiese M, Rioult-Pedotti MS, et al. Dopamine in motor cortex is necessary for skill learning and synaptic plasticity. PLoS One 2009;4:e7082.

93. Hosp JA, Pekanovic A, Rioult-Pedotti MS, Luft AR. Dopaminergic projections from midbrain to primary motor cortex mediate motor skill learning. J Neurosci 2011;31:2481-2487.

94. Floel $A$, Cohen LG. Recovery of function in humans: cortical stimulation and pharmacological treatments after stroke. Neurobiol Dis 2010;37:243-251.

95. Scheidtmann K, Fries W, Müller F, Koenig E. Effect of levodopa in combination with physiotherapy on functional motor recovery after stroke: a prospective, randomised, doubleblind study. Lancet 2001;358:787-790.

96. Pearson-Fuhrhop KM, Minton B, Acevedo D, Shahbaba B, Cramer SC. Genetic variation in the human brain dopamine system influences motor learning and its modulation by LDopa. PLoS One 2013;8:e61197.

97. MacDonald HJ, Stinear CM, Ren A, Coxon JP, Kao J, Macdonald $L$, et al. Dopamine gene profiling to predict impulse control and effects of dopamine agonist ropinirole. J Cogn Neurosci 2016;28:909-919.

98. Cramer SC, Dobkin BH, Noser EA, Rodriguez RW, Enney LA. Randomized, placebo-controlled, double-blind study of ropinirole in chronic stroke. Stroke 2009;40:3034-3038.

99. Small SL, Llano DA. Biological approaches to aphasia treatment. Curr Neurol Neurosci Rep 2009;9:443-450.

100. Wang LE, Fink GR, Diekhoff S, Rehme AK, Eickhoff SB, Grefkes $C$. Noradrenergic enhancement improves motor network connectivity in stroke patients. Ann Neurol 2011;69:375-388.

101. Fasotti $L$, van Kessel M. Novel insights in the rehabilitation of neglect. Front Hum Neurosci 2013;7:780.

102. Cools R, Roberts AC, Robbins TW. Serotoninergic regulation of emotional and behavioural control processes. Trends Cogn 
Sci 2008;12:31-40.

103. Logue SF, Gould TJ. The neural and genetic basis of executive function: attention, cognitive flexibility, and response inhibition. Pharmacol Biochem Behav 2014;123:45-54.

104. Cowen P, Sherwood AC. The role of serotonin in cognitive function: evidence from recent studies and implications for understanding depression. J Psychopharmacol 2013;27:575-583.

105. Dam M, Tonin P, De Boni A, Pizzolato G, Casson S, Ermani M, et al. Effects of fluoxetine and maprotiline on functional recovery in poststroke hemiplegic patients undergoing rehabilitation therapy. Stroke 1996;27:1211-1214.

106. Miyai I, Reding MJ. Effects of antidepressants on functional recovery following stroke: a double-blind study. Neurorehabil Neural Repair 1998;12:5-13.

107. Pariente J, Loubinoux I, Carel C, Albucher JF, Leger A, Manelfe $C_{1}$ et al. Fluoxetine modulates motor performance and cerebral activation of patients recovering from stroke. Ann Neurol 2001;50:718-729.

108. Fruehwald S, Gatterbauer E, Rehak P, Baumhackl U. Early fluoxetine treatment of post-stroke depression: a threemonth double-blind placebo-controlled study with an openlabel long-term follow up. J Neurol 2003;250:347-351.

109. Robinson RG, Jorge RE, Moser DJ, Acion L, Solodkin A, Small $S L$, et al. Escitalopram and problem-solving therapy for prevention of poststroke depression: a randomized controlled trial. JAMA 2008;299:2391-2400.

110. Mikami $K$, Jorge RE, Moser DJ, Arndt $S$, Jang $M$, Solodkin $A$, et al. Prevention of post-stroke generalized anxiety disorder, using escitalopram or problem-solving therapy. J Neuropsychiatry Clin Neurosci 2014;26:323-328.

111. Chollet F, Tardy J, Albucher JF, Thalamas C, Berard E, Lamy C, et al. Fluoxetine for motor recovery after acute ischaemic stroke (FLAME): a randomised placebo-controlled trial. Lancet Neurol 2011;10:123-130.

112. Kato $M$, Serretti A. Review and meta-analysis of antidepressant pharmacogenetic findings in major depressive disorder. Mol Psychiatry 2010;15:473-500.

113. Kohen R, Cain KC, Buzaitis A, Johnson V, Becker KJ, Teri $L$, et al. Response to psychosocial treatment in poststroke depression is associated with serotonin transporter polymorphisms. Stroke 2011;42:2068-2070.

114. Kim JS, Lee EJ, Chang DI, Park JH, Ahn SH, Cha JK, et al. Efficacy of early administration of escitalopram on depressive and emotional symptoms and neurological dysfunction after stroke: a multicentre, double-blind, randomised, placebocontrolled study. Lancet Psychiatry 2017;4:33-41.

115. Merzenich MM, Van Vleet TM, Nahum M. Brain plasticitybased therapeutics. Front Hum Neurosci 2014;8:385.
116. Beltran EJ, Papadopoulos CM, Tsai SY, Kartje GL, Wolf WA. Long-term motor improvement after stroke is enhanced by short-term treatment with the alpha-2 antagonist, atipamezole. Brain Res 2010;1346:174-182.

117. Zittel S, Weiller $C_{1}$ Liepert J. Reboxetine improves motor function in chronic stroke. A pilot study. J Neuro/ 2007;254:197201.

118. Baskerville KA, Schweitzer JB, Herron P. Effects of cholinergic depletion on experience-dependent plasticity in the cortex of the rat. Neuroscience 1997;80:1159-1169.

119. Luria AR. Restoration of Function after Brain Injury. Oxford, UK: Macmillan, 1963.

120. Kilgard MP, Merzenich MM. Cortical map reorganization enabled by nucleus basalis activity. Science 1998;279:17141718.

121. Wang L, Conner JM, Nagahara AH, Tuszynski MH. Rehabilitation drives enhancement of neuronal structure in functionally relevant neuronal subsets. Proc Natl Acad Sci U S A 2016;113: 2750-2755.

122. Ramanathan $\mathrm{D}$, Tuszynski MH, Conner JM. The basal forebrain cholinergic system is required specifically for behaviorally mediated cortical map plasticity. J Neurosci 2009;29:5992-6000.

123. Berthier $M L$, Green $C_{1}$ Higueras $C_{1}$ Fernández I, Hinojosa J, Martín MC. A randomized, placebo-controlled study of donepezil in poststroke aphasia. Neurology 2006;67:16871689.

124. Barrett KM, Brott TG, Brown RD Jr, Carter RE, Geske JR, GraffRadford NR, et al. Enhancing recovery after acute ischemic stroke with donepezil as an adjuvant therapy to standard medical care: results of a phase IIA clinical trial. J Stroke Cerebrovasc Dis 2011;20:177-182.

125. Nadeau SE, Behrman AL, Davis SE, Reid K, Wu SS, Stidham BS, et al. Donepezil as an adjuvant to constraint-induced therapy for upper-limb dysfunction after stroke: an exploratory randomized clinical trial. J Rehabil Res Dev 2004;41:525-534.

126. Whyte EM, Lenze EJ, Butters $M$, Skidmore $E_{1}$ Koenig $K$, Dew $M A$, et al. An open-label pilot study of acetylcholinesterase inhibitors to promote functional recovery in elderly cognitively impaired stroke patients. Cerebrovasc Dis 2008;26:317-321.

127. López-Valdés HE, Clarkson AN, Ao Y, Charles AC, Carmichael ST, Sofroniew MV, et al. Memantine enhances recovery from stroke. Stroke 2014;45:2093-2100.

128. Zhang R, Wang Y, Zhang L, Zhang Z, Tsang W, Lu M, et al. Sildenafil (Viagra) induces neurogenesis and promotes functional recovery after stroke in rats. Stroke 2002;33:2675-2680.

129. Bednar MM. The role of sildenafil in the treatment of stroke. Curr Opin Investig Drugs 2008;9:754-759.

130. Silver B, McCarthy S, Lu M, Mitsias P, Russman AN, Katrama- 
$\operatorname{dos} A$, et al. Sildenafil treatment of subacute ischemic stroke: a safety study at 25-mg daily for 2 weeks. J Stroke Cerebrovasc Dis 2009;18:381-383.

131. Lindvall 0, Kokaia Z. Stem cell research in stroke: how far from the clinic? Stroke 2011;42:2369-2375.

132. Savitz SI, Cramer SC, Wechsler L; STEPS 3 Consortium. Stem cells as an emerging paradigm in stroke 3 : enhancing the development of clinical trials. Stroke 2014;45:634-639.

133. Eckert MA, Vu O, Xie K, Yu J, Liao W, Cramer SC, et al. Evidence for high translational potential of mesenchymal stromal cell therapy to improve recovery from ischemic stroke. $J$ Cereb Blood Flow Metab 2013;33:1322-1334.

134. Li Y, Chopp M. Marrow stromal cell transplantation in stroke and traumatic brain injury. Neurosci Lett 2009;456:120-123.

135. Phinney DG, Prockop DJ. Concise review: mesenchymal stem/ multipotent stromal cells: the state of transdifferentiation and modes of tissue repair: current views. Stem Cells 2007;25:2896-2902.

136. Honmou O, Onodera R, Sasaki M, Waxman SG, Kocsis JD. Mesenchymal stem cells: therapeutic outlook for stroke. Trends Mol Med 2012;18:292-297.

137. Vu Q, Xie K, Eckert M, Zhao W, Cramer SC. Meta-analysis of preclinical studies of mesenchymal stromal cells for ischemic stroke. Neurology 2014;82:1277-1286.

138. Bang OY, Lee JS, Lee PH, Lee G. Autologous mesenchymal stem cell transplantation in stroke patients. Ann Neurol 2005;57:874882.

139. Yavagal DR, Lin B, Raval AP, Garza PS, Dong C, Zhao W, et al. Efficacy and dose-dependent safety of intra-arterial delivery of mesenchymal stem cells in a rodent stroke model. PLoS One 2014;9:e93735.

140. Kalladka D, Sinden J, Pollock K, Haig C, McLean J, Smith W, et al. Human neural stem cells in patients with chronic ischaemic stroke (PISCES): a phase 1, first-in-man study. Lancet 2016;388:787-796.

141. Steinberg GK, Kondziolka D, Wechsler LR, Lunsford LD, Coburn $\mathrm{ML}$, Billigen JB, et al. Clinical outcomes of transplanted modified bone marrow-derived mesenchymal stem cells in stroke: a phase 1/2a study. Stroke 2016;47:1817-1824.

142. Hess DC, Wechsler LR, Clark WM, Savitz SI, Ford GA, Chiu D, et al. Safety and efficacy of multipotent adult progenitor cells in acute ischaemic stroke (MASTERS): a randomised, double-blind, placebo-controlled, phase 2 trial. Lancet Neurol 2017;16:360-368.

143. Hyun I. The bioethics of stem cell research and therapy. J Clin Invest 2010;120:71-75.

144. Wolf SL, Winstein CJ, Miller JP, Taub E, Uswatte G, Morris D, et al. Effect of constraint-induced movement therapy on up- per extremity function 3 to 9 months after stroke: the EXCITE randomized clinical trial. JAMA 2006;296:2095-2104.

145. Wolf SL, Winstein CJ, Miller JP, Thompson PA, Taub E, Uswatte $\mathrm{G}$, et al. Retention of upper limb function in stroke survivors who have received constraint-induced movement therapy: the EXCITE randomised trial. Lancet Neurol 2008;7:33-40.

146. Berthier ML, Pulvermüller F. Neuroscience insights improve neurorehabilitation of poststroke aphasia. Nat Rev Neurol 2011;7:86-97.

147. Dromerick AW, Lang CE, Powers WJ, Wagner JM, Sahrmann SA, Videen TO, et al. Very Early Constraint-Induced Movement Therapy (VECTORS): phase II trial results. Stroke 2007;38:465.

148. Duncan PW, Sullivan KJ, Behrman AL, Azen SP, Wu SS, Nadeau SE, et al. Body-weight-supported treadmill rehabilitation after stroke. N Engl J Med 2011;364:2026-2036.

149. Winstein CJ, Wolf SL, Dromerick AW, Lane CJ, Nelsen MA, Lewthwaite $R$, et al. Effect of a task-oriented rehabilitation program on upper extremity recovery following motor stroke: the ICARE randomized clinical trial. JAMA 2016;315:571581.

150. Lang $C E$, Strube MJ, Bland MD, Waddell KJ, Cherry-Allen KM, Nudo RJ, et al. Dose response of task-specific upper limb training in people at least 6 months poststroke: a phase II, singleblind, randomized, controlled trial. Ann Neurol 2016;80:342354.

151. Brewer BR, McDowell SK, Worthen-Chaudhari LC. Poststroke upper extremity rehabilitation: a review of robotic systems and clinical results. Top Stroke Rehabil 2007;14:22-44.

152. Volpe BT, Huerta PT, Zipse JL, Rykman A, Edwards D, Dipietro $L$, et al. Robotic devices as therapeutic and diagnostic tools for stroke recovery. Arch Neurol 2009;66:1086-1090.

153. Reinkensmeyer DJ, Emken JL, Cramer SC. Robotics, motor learning, and neurologic recovery. Annu Rev Biomed Eng 2004; 6:497-525.

154. Balasubramanian S, Klein J, Burdet E. Robot-assisted rehabilitation of hand function. Curr Opin Neurol 2010;23:661-670.

155. Veerbeek JM, Langbroek-Amersfoort AC, van Wegen EE, Meskers CG, Kwakkel G. Effects of robot-assisted therapy for the upper limb after stroke. Neurorehabil Neural Repair 2017;31:107-121.

156. Cramer SC. Brain repair after stroke. N Engl J Med 2010;362: 1827-1829.

157. Lo AC, Guarino PD, Richards LG, Haselkorn JK, Wittenberg GF, Federman DG, et al. Robot-assisted therapy for long-term upper-limb impairment after stroke. N Engl J Med 2010;362:17721783.

158. Dobkin $\mathrm{BH}$. A rehabilitation-internet-of-things in the home to augment motor skills and exercise training. Neurorehabil Neural Repair 2017;31:217-227. 
159. Chen J, Jin W, Zhang XX, Xu W, Liu XN, Ren CC. Telerehabilitation approaches for stroke patients: systematic review and meta-analysis of randomized controlled trials. J Stroke Cerebrovasc Dis 2015;24:2660-2668.

160. Levy $C E_{1}$ Silverman $E_{1}$ Jia $H$, Geiss $M$, Omura D. Effects of physical therapy delivery via home video telerehabilitation on functional and health-related quality of life outcomes. $J$ Rehabil Res Dev 2015;52:361-370.

161. Choi YH, Park HK, Paik NJ. A telerehabilitation approach for chronic aphasia following stroke. Telemed J E Health 2016;22: 434-440.

162. Putrino D. Telerehabilitation and emerging virtual reality approaches to stroke rehabilitation. Curr Opin Neuro/ 2014;27:631636.

163. Agostini M, Moja L, Banzi R, Pistotti $V$, Tonin P, Venneri A, et al. Telerehabilitation and recovery of motor function: a systematic review and meta-analysis. J Telemed Telecare 2015;21:202213.

164. Dodakian L, McKenzie AL, Le V, See J, Pearson-Fuhrhop K,

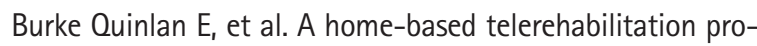
gram for patients with stroke. Neurorehabil Neural Repair 2017;31:923-933.

165. ClinicalTrials.gov. Telerehabilitation in the Home versus therapy in-clinic for patients with stroke. https://clinicaltrials. gov/ct2/show/NCT02360488. 2015. Accessed January 19, 2018.

166. Edwardson MA, Lucas TH, Carey JR, Fetz EE. New modalities of brain stimulation for stroke rehabilitation. Exp Brain Res 2013;224:335-358.

167. Dawson J, Pierce D, Dixit A, Kimberley TJ, Robertson M, Tarver $B$, et al. Safety, feasibility, and efficacy of vagus nerve stimulation paired with upper-limb rehabilitation after ischemic stroke. Stroke 2016;47:143-150.

168. American Psychiatric Association. Practice Guideline for the Treatment of Patients with Major Depressive Disorder. 3rd ed. Arlington, VA: American Psychiatric Association, 2010.

169. McClintock SM, Reti IM, Carpenter LL, McDonald WM, Dubin M, Taylor SF, et al. Consensus recommendations for the clinical application of repetitive transcranial magnetic stimulation (rTMS) in the treatment of depression. J Clin Psychiatry. 2017 May 23 [Epub]. https://doi.org/10.4088/JCP.16cs10905.

170. Lindenberg R, Zhu LL, Rüber T, Schlaug G. Predicting func- tional motor potential in chronic stroke patients using diffusion tensor imaging. Hum Brain Mapp 2012;33:1040-1051.

171. Ackerley SJ, Stinear CM, Barber PA, Byblow WD. Combining theta burst stimulation with training after subcortical stroke. Stroke 2010;41:1568-1572.

172. Levy R, Benson R, Winstein C; for the Everest Study Investigators. Cortical stimulation for upper-extremity hemiparesis from ischemic stroke: everest study primary endpoint results. Presented at International Stroke Conference 2008; 2008 Feb 20-22; New Orleans, LA.

173. Pomeroy VM, Cloud G, Tallis RC, Donaldson C, Nayak V, Miller $\mathrm{S}$. Transcranial magnetic stimulation and muscle contraction to enhance stroke recovery: a randomized proof-of-principle and feasibility investigation. Neurorehabil Neural Repair 2007;21:509-517.

174. Levy RM, Harvey RL, Kissela BM, Winstein CJ, Lutsep HL, Parrish $\mathrm{TB}_{\mathrm{B}}$ et al. Epidural electrical stimulation for stroke rehabilitation: results of the prospective, multicenter, randomized, single-blinded everest trial. Neurorehabil Neural Repair 2016;30:107-119.

175. Kleim JA, Jones TA. Principles of experience-dependent neural plasticity: implications for rehabilitation after brain damage. J Speech Lang Hear Res 2008;51:S225-S239.

176. Cramer SC, Sur M, Dobkin BH, O'Brien C, Sanger TD, Trojanowski JQ, et al. Harnessing neuroplasticity for clinical applications. Brain 2011;134(Pt 6):1591-1609.

177. Cramer SC. An overview of therapies to promote repair of the brain after stroke. Head Neck 2011;33 Suppl 1:S5-S7.

178. Bernhardt J, Borschmann K, Boyd L, Carmichael ST, Corbett D, Cramer SC, et al. Moving rehabilitation research forward: developing consensus statements for rehabilitation and recovery research. Neurorehabil Neural Repair 2017;31:694698.

179. Bernhardt J, Hayward KS, Kwakkel G, Ward NS, Wolf SL, Borschmann $K_{1}$ et al. Agreed definitions and a shared vision for new standards in stroke recovery research: the Stroke Recovery and Rehabilitation Roundtable taskforce. Int J Stroke 2017;12:444-450.

180. Cramer SC, Wolf SL, Adams HP Jr, Chen D, Dromerick AW,

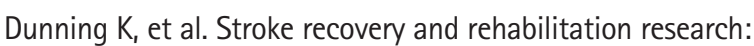
issues, opportunities, and the National Institutes of Health StrokeNet. Stroke 2017;48:813-819. 